\title{
In vitro evaluation of chitosan-DNA plasmid complex encoding Jembrana disease virus Env-TM protein as a vaccine candidate
}

\author{
Januar Ishak ${ }^{1}$, Lalu Unsunnidhal ${ }^{1}$, \\ Ronny Martien ${ }^{2}$, Asmarani Kusumawati ${ }^{1,3}$ \\ ${ }^{1}$ Research Center for Biotechnology, ${ }^{2}$ Department of Pharmaceutics, \\ ${ }^{3}$ Department of Reproduction and Obstetrics, Faculty of Veterinary Medicine, \\ University Gadjah Mada, Yogyakarta, 55281, Indonesia \\ asmaranikusumawati2018@gmail.com
}

Received: September 27, 2018

Accepted: March 1, 2019

\begin{abstract}
Introduction: The development of Jembrana disease vaccine is an important effort to prevent losses in the Bali cattle industry in Indonesia. This study aims to prepare a Jembrana DNA vaccine encoding the transmembrane portion of the envelope protein in pEGFP-C1 and test the success of its delivery in culture cells using a chitosan-DNA complex. Material and Methods: Cloning of the DNA vaccine was successfully performed on E. coli DH5 $\alpha$ and confirmed by colony PCR, restriction analysis and sequencing. The plasmids were prepared as a chitosan complex using the complex coacervation method and physicochemically characterised using a particle size analyser. A transfection assay was performed in HeLa cells with $4 \mathrm{~h}$ exposure, and mRNA expression was assessed at $24 \mathrm{~h}$ post transfection. Results: With a 1:2 (wt./wt.) ratio of DNA and chitosan, the complexes have a mean diameter of $236 \mathrm{~nm}$, zeta potential value of $+17.9 \mathrm{mV}$, and showed no high toxicity potential in the HeLa cells. This complex successfully delivered the DNA into cells, as shown by the presence of a specific RT-PCR product (336 bp). However, the real-time PCR analysis showed that the delivery with chitosan complex resulted in lower target mRNA expression when compared with a commercial transfecting agent. Conclusion: pEGFP-env-tm JDV as a candidate vaccine can be delivered as the chitosan-DNA complex and be expressed at the transcription level in vitro. This initial study will be used for further improvement and evaluation in vivo.
\end{abstract}

Keywords: chitosan-DNA complex, env gene, Jembrana disease virus, pEGFP-C1, vaccine.

\section{Introduction}

Jembrana disease virus (JDV) is a lentivirus that causes jembrana disease specifically in Balinese cattle from Indonesia (25). At first, this disease was reported in Jembrana District of Bali Island in 1964, but it has since been found in other regions of Indonesia, such as Lampung, West Sumatra, or East Java (10), and it has even been detected in Australia (3). Jembrana disease virus is currently able to infect Balinese cattle virulently, but it can also infect other cattle breeds such as Friesian cattle (Bos taurus) and crossbred Bali cattle (Bos javanicus $\times$ Bos indicus), though with milder symptoms (22). The economic loss caused by this disease is exemplified by the death of 50,000 Balinese cattle in one year during the first outbreak in Indonesia (1). This virus is closely related to HIV. It triggers an acute disease in infected cattle with a short incubation period, rapidly replicates in the blood with extremely high titres, and leads to death within 1-2 weeks (24). Moreover, the expected mortality rate is about $17 \%$ (4), causing Jembrana disease to be one of the main concerns in the Balinese cattle industry.

Biotechnology is able to overcome the problem of Jembrana disease by contributing to the development of a vaccine. Primarily the vaccine is to prevent losses in the livestock industry, but in addition efforts to develop livestock-related vaccines to animal lentiviruses are often intended to serve as model studies in the development of more effective HIV vaccines $(5,19)$. 
Biotechnology is able to provide a wide range of vaccine types depending on the injected molecule, but the DNA-type vaccine is considered potentially applicable in cases of viral diseases. The use of the DNA molecule avoids the possibility of reversal of the attenuation and the pathogen being virulent again or avoids the risk of failure of a pathogen's inactivation process (26). As a key difference from other types of vaccines that are only capable of triggering a humoral immune response, DNA vaccines are capable of triggering a cellular immune response as well (28), which is a critical response for the successful control of viral infections within the organism.

Although the DNA vaccine is promising, it has low efficacy in inducing the immune system due to the limitation in its delivery system (23). In intramuscular injection of DNA vaccines, DNA molecules fail to enter antigen-presenting cells (APCs) and induce immune responses because nucleic acids only penetrate cell membranes with great difficulty (18). Chitosan and its derivatives are some of the most widely used natural polymers for drug or DNA delivery for gene therapy (11). Due to the presence of amino groups, chitosan has a positive charge so that it can adhere to negatively charged DNA forming a complex and protect it from nuclease degradation. Biocompatible chitosan also helps to facilitate DNA penetration of cell phospholipid membranes both in vitro and in vivo and can be degraded with nuclease in serum (11).

The commercial Jembrana disease vaccine that is available and routinely used in Indonesia, namely JDVacc, is still prepared from JDV-infected cattle spleen homogenates that have been inactivated using Triton X-100 detergent and emulsified with mineral oil adjuvant (MOA) (7). The need for a more effective vaccine serves as the background for the development of a new DNA vaccine which is formulated as a chitosan-DNA complex. Nucleic acid delivery is one of the vaccine delivery systems currently meriting exploration. The target genes for the development of a Jembrana DNA vaccine include env-tm that encodes the transmembrane portion of envelope glycoprotein. This domain plays an important role in the fusion of the virus sheath with the host cell membrane, which in turn permits the successful entry of the virus into the host cell (2). This protein has a very conservative sequence of inter-strains and is immunogenic; it is considered one of the major immunodominant parts of the JDV (6). Homologous recombinant envelope proteins have been reported previously to give partial protection in a challenge experiment with feline immunodeficiency virus in cats (15) and equine infectious anaemia virus in horses (12).

\section{Material and Methods}

Materials. The gene encoding transmembrane portion of envelope protein from JDV which had previously been isolated from infected cattle was cloned into the pCR2.1 vector (14) and confirmed using Sanger sequencing (supplementary data 1). The gene was optimised to be expressed in the Bos taurus host, chemically synthesised, and cloned into the plasmid enhanced green fluorescent protein $\mathrm{C}$ terminus (pEGFP-C1) vector (Clontech, USA) by Gene Universal Inc. services (China) to construct pEGFPenv-tm JDV. Chitosan of medium molecular weight with deacetylation degree of $75 \%-85 \%$ and viscosity of 200-800 cps was purchased from Sigma (Singapore). Two different commercial transfecting agents were used as positive control: Lipofectamine 3000 Reagent (Invitrogen, USA) as liposomal transfecting agent and TransIntro EL Transfection Reagent (TransGen Biotech, China) as a non-liposomal transfecting agent. The different primers used for PCR or real-time PCR in this experiment are listed in Table 1.

Table 1. List of primers used for the PCR amplification

\begin{tabular}{|c|c|c|c|}
\hline Primer name & Nucleotide sequence & Expected product size & Method \\
\hline Env-For ${ }^{\mathrm{a}}$ & 5'CAGACTGAGCACCAACCTGA3' & \multirow{3}{*}{$336 \mathrm{bp}$} & \multirow{3}{*}{ Colony-PCR and real-time PCR } \\
\hline & & & \\
\hline Env-Rev ${ }^{a}$ & 5'GTGTTGCTCTTGCCCTTCTC3' & & \\
\hline EGFP-C ${ }^{b}$ & 5'CATGGTCCTGCTGGAGTTCGTG3' & \multirow{3}{*}{$1382 \mathrm{bp}$} & \multirow{3}{*}{ Sequencing } \\
\hline & & & \\
\hline $\mathrm{SV}_{40} \mathrm{pA}^{\mathrm{b}}$ & 5'GAAATTTGTGATGCTATTGC3' & & \\
\hline GAPDH-For ${ }^{\mathrm{c}}$ & 5'GAAGGTGAAGGTCGGAGTC3' & \multirow[t]{2}{*}{226 bp } & \multirow[t]{2}{*}{ Real-time PCR } \\
\hline GAPDH-Rev ${ }^{c}$ & 5'GAAGATGGTGATGGGATTTC3' & & \\
\hline
\end{tabular}


Gene design for DNA vaccine. The isolated gene of env-tm was optimised to be expressed in a Bos taurus host using codon optimisation. Codon optimisation is done without changing the amino acid sequence to prevent the changing of antigenicity from native protein. Some unique sequences that give lower expression such as GCTGGTGG (Chi site) GTTGTAAC (ter site core), AATAAA dan ATTAAA (polyA sites), TATA (consensus eukaryotic promoter core), TTAGGG (immunosuppressive telomeric motif), GCCGTCTGAA, AAGTGCGGT and ACAAGCGGTC (DNA uptake sequences), AGGT (consensus splice donor), CAGG (consensus splice acceptor), AAAAA (polyA binding proteins consensus) TTTTT (polyT binding proteins consensus), and TTATCCACA (DnaA binding site) were removed using codon optimisation (26). Then, the transgene was chemically synthesised with restriction sites of $B g l \mathrm{II}$ and $E c o R I$ and cloned into the pEGFP-C1 vector (Clontech) by Gene Universal Inc., resulting in pEGFP-env-tm JDV (Fig. 1).

Plasmid preparation. The plasmid pEGFP-envtm JDV was transformed into chemically competent E. coli $\mathrm{DH} 5 \alpha$ using a heat-shock procedure and then screened in Luria-Bertani agar selective medium (HiMedia, India) containing $50 \mu \mathrm{g} / \mathrm{mL}$ of kanamycin. Kanamycin-resistant bacteria were checked by colonyPCR with Env-For and Env-Rev primers. The selected positive clones were confirmed using restriction analysis with EcoRI (Invitrogen, USA) and BglII (Invitrogen). The clone that gave a positive result from the colony-PCR and restriction digestion was selected to undergo further confirmation with sequencing using EGFP-C and SV40pA primers. The selected clone successfully carrying the desired plasmid was cultured in $200 \mathrm{~mL}$ of Luria-Bertani broth (HiMedia) containing
Kanamycin $50 \mu \mathrm{g} / \mathrm{mL}$ overnight at $37^{\circ} \mathrm{C}$ in an incubator shaker set to $150 \mathrm{rpm}$. Plasmids were prepared using FavorPrep Plasmid Extraction Maxi Kit (Favorgen Biotech Corp, Taiwan). The extracted DNA plasmid concentration was measured with a MaestroGen MaestroNano Spectrophotometer (Maestrogen, Taiwan).

Chitosan-DNA complex preparation. Firstly, $20 \mathrm{mg}$ of medium molecular weight chitosan was dissolved in $100 \mathrm{~mL}$ of $1 \%(\mathrm{v} / \mathrm{v})$ acetic acid. The $\mathrm{pH}$ of the solution was adjusted to 5.0 by addition of $5 \mathrm{M}$ $\mathrm{NaOH}$. The chitosan solution was then sterilised using a $0.2 \mu \mathrm{m}$ syringe filter (Merck, Germany) and was used as a stock to make chitosan-DNA complex. The preparation of chitosan-DNA complex was performed with the complex coacervation method with modifications (16). A total amount of $1 \mu \mathrm{g}$ plasmid and different amounts of chitosan were heated separately at $50^{\circ} \mathrm{C}$ for $10 \mathrm{~min}$. Then, plasmid and chitosan solution were mixed with a volume ratio of $1: 1$ by vortexing at $2,500 \mathrm{rpm}$ for $30 \mathrm{~s}$. The mass ratios of DNA and chitosan used were 1:0.5, 1:1.0, 1:2.0, 1:3.0, and 1:4.0 (wt./wt.). The formation of chitosan-DNA complex was examined using a gel retardation assay in agarose gel electrophoresis. The chitosan-DNA complexes were electrophoresed on a $0.8 \%$ agarose gel with Gel Stain (TransGen Biotech, China). Unbound DNA and chitosan solution were used as negative controls.

Physicochemical characterisation. The mean particle size was measured with an SZ-100 nanoparticle analyser (Horiba Scientific, UK) at $24.9^{\circ} \mathrm{C}$ and scattering angle $90^{\circ} \mathrm{C}$. The zeta potential measurement of chitosan complex was performed with the same nanoparticle analyser at $24.8^{\circ} \mathrm{C}$ and electrode voltage $3.3 \mathrm{~V}$.

A GCCGTGGGAATGGTGATCTTCCTGCTGGTGCTGGCCATCATGGCCATGACCGCCTCCGTGACCGCCGCTGCTACCCTGGTG AAGCAGCACGCCACCGCCCAAGTTGTGGGCAGACTGAGCACCAACCTGACCTACATCACCAAGATCCAGAACCAGTACC TGCACCTGTTCCAGAACCTGAACACCCGGGTGAACAACCTGCACCACCGGGTGACCTACCTGGAGTTCCTGGCCGAAGTT CACGAAGTTCAGACCGGCCTGGGCTGCGTGCCCAGAGGAAGATACTGCCACTTCGACTGGAGGCCCGAGGAAGTTGGCC TGAACATGACCCTGTGGAACTCCACCACCTGGCAGCAGTGGATGAGCTACTACGACCAGATCGAGGAGAACATCTGGAA CCTGAAGTACAACTGGAGCGAGGCCCTGGAGAAGGGCAAGAGCAACACCGACGGCCTGGAGCCCGACGTGTTCAGATAC CTGGCCGACCTGAGCAGCTCCTTCACCTGGGGCTCCTGGGTGGACAAGCTGGTGTGGCTGGCCTACATCCTGCTGGCCTA CTTCGCCTTCAAAGTTCTGCAGTGCATCATGAGCAACCTGGGCGCCCAGACCCGGTACCAGCTGCTGAACGCCCAAGAAG ACACCGACCCCGCCGGCGATGGCGATCAGCCTGATGACCACCGGTCCGGCGACACCCCTAGGAGTGGAGTGCCCTCCGG CGGATGGAGCCAGAAGCTGTCCGAGGGCAAGAAGATCGGCTGCCTGATCCTGCGGACCGAGTGGCAGAACTGGCGGAAC GACCTGCGGACCCTGCGGTGGCTGACCCTGGGAGGAAAGATCCTGCAGCTGCCCCTGAGCCTGCTGGTGCTCCTGGTGAG AATCCTGCTGCACATCCTGAGCCCCACCTTCCAGAACCAGAGGGGCTGGACCGTGGGCAGAAAGGGCACCGGAGGCGAC GACAGAGAGCTGTCCCCCGAGCTGGAGTACCTGAGCTGGACCGGCTCCTCCCAAGAAATGGTGGAGATGCGGGACCTGA AGGAGGAGGACATCCCCGAGGAGGGCATCCGCCCTGTGGAGATG

B.



Fig. 1. Gene design for DNA vaccine. A - The optimised sequence of env-tm JDV with red characters showing the substituted nucleotide for codon optimisation. B - Cloning strategy to insert the synthetic gene into plasmid pEGFP-C1 with in-frame reading with the coding sequence of GFP protein, resulting in fusion protein GFP-Env-TM 
Commercial transfecting agent preparation. Two commercial transfecting agents were used as positive controls. The first agent was cationic liposome complex (Lipofectamine 3000 Reagent, Invitrogen, USA), and the other was non-liposomal transfecting agent (TransIntro EL Transfecting Reagent, TransGen Biotech, China). Preparation of liposome complex was performed by diluting a total of $6 \mu \mathrm{L}$ of the Lipofectamine 3000 Reagent in $250 \mu \mathrm{L}$ of Roswell Park Memorial Institute medium without serum and mixing using a vortex for $2-3 \mathrm{~s}$. A total of $4 \mu \mathrm{g}$ of plasmid DNA was diluted in $250 \mu \mathrm{L}$ of Dulbecco's modified Eagle's medium (DMEM) without serum in a separate sterile tube and $8 \mu \mathrm{L}$ of P3000 reagent was added. Then, the diluted DNA solution was added slowly into the diluted Lipofectamine solution (volume ratio of 1:1) and mixed well. The final mixture was incubated for $15 \mathrm{~min}$ at room temperature. The complex was then ready for use and was included in $1 \mathrm{~mL}$ of final culture cell media that had been grown by HeLa cells. The non-liposomal transfecting agent was prepared by diluting $4 \mu \mathrm{g}$ of plasmid DNA in $50 \mu \mathrm{L}$ of DMEM without serum. After that, $8 \mu \mathrm{L}$ of pre-mix TransIntro EL was added into the tube of diluted DNA, mixed well, and incubated at room temperature for 15-20 min. The complex was ready for use and was included in $1 \mathrm{~mL}$ of final culture cell media.

Cytotoxicity assay. Prior to transfection assay, a cytotoxicity assay was performed to ensure that the chitosan complexes did not have high toxicity potential for the cell. Viable cells in the samples that were treated with DNA, chitosan, and chitosan-DNA complex were measured using the MTT assay (Table 2). The HeLa cells were seeded in a 96-well plate at an initial density of $5 \times 10^{3}$ cells per well in $200 \mu \mathrm{L}$ of supplemented DMEM medium for $24 \mathrm{~h}$. Cells were then incubated with DNA plasmid only, chitosan, and chitosan-DNA complex for $4 \mathrm{~h}$. Untreated cells were used as negative control. After incubation, the medium was replaced with fresh supplement DMEM and incubated for another $24 \mathrm{~h}$. Then, the medium was replaced by $100 \mu \mathrm{L}$ of MTT stock solution per well. The cells were incubated for $3 \mathrm{~h}$ along with the reagent at $37^{\circ} \mathrm{C}$ in a $5 \% \mathrm{CO}_{2}$ incubator. The stopper reagent $(10 \% \mathrm{SDS})$ was added to dissolve the blue-violet crystals. Absorbance of the dye was measured at the wavelength of $500 \mathrm{~nm}$ with an ELISA reader. The relative viability was calculated according to absorbance of the dye in untreated cells.

In vitro transfection assay and GFP protein expression. HeLa cells were selected as a model for in vitro transfection studies to simulate the uptake of chitosan nanoparticle by eukaryotic cells. HeLa cells were maintained at $37^{\circ} \mathrm{C}$ under $5 \% \mathrm{CO}_{2}$ in DMEM medium supplemented with $10 \%(\mathrm{v} / \mathrm{v})$ foetal bovine serum, penicillin $(100 \mathrm{U} / \mathrm{mL})$, and streptomycin $(100 \mathrm{mg} / \mathrm{mL})$. HeLa cells were seeded on a $35 \mathrm{~mm}$ Petri culture dish and incubated for $48 \mathrm{~h}$ until reaching 70\%$90 \%$ confluency. The culture medium was removed and substituted with fresh medium containing a defined concentration of chitosan nanoparticles. For the observation of GFP protein expression, the cells were treated with chitosan only, with DNA plasmid only, plasmid NTC8685-eGFP (positive control plasmid) (Nature Technology, USA) with cationic liposomal transfecting agent, plasmid pEGFP-env-tm JDV with cationic liposomal transfecting agent, and plasmid pEGFP-env-tm JDV in the form of chitosan-DNA complex (Table 2). The treatments were incubated for $4 \mathrm{~h}$ after which the intracellular uptake of DNA was examined with the same amount $(4 \mu \mathrm{g})$. After incubation, the medium was changed for fresh medium. Culture cells were examined under an LSM 800 confocal microscope (Zeiss 800 , Germany) after $24 \mathrm{~h}$ to observe the expression of the GFP-Env-TM fusion protein.

Qualitative detection of target mRNA in transfected HeLa cells. Transfected culture cells with some treatments (Table 2) were also harvested manually after $24 \mathrm{~h}$ incubation using disposable cell scrapers. Then, the cells were precipitated using centrifugation at 2,500 $\mathrm{g}$ for $5 \mathrm{~min}$ and washed twice using cold sterile PBS. The total RNA of culture cells was extracted using an RNeasy Mini Kit (Qiagen, Germany), and cDNAs were synthesised from the total RNAs using High Capacity cDNA Reverse Transcription Kits (Applied Biosystems, USA). The thermal cycler conditions for cDNA synthesis were as follows: $25^{\circ} \mathrm{C}$ for $10 \mathrm{~min}, 37^{\circ} \mathrm{C}$ for $120 \mathrm{~min}, 85^{\circ} \mathrm{C}$ for $5 \mathrm{~min}$, and $4^{\circ} \mathrm{C}$ for hold during storage. Next was the amplification of target cDNA using the Env-For and Env-Rev primers with GoTaq Green Master Mix (Promega, USA). The cDNA was diluted as much as $10 \times$ using nuclease-free water before being used as the template in the PCR. The thermal cycler conditions for this amplification were as follows: pre-denaturation at $95^{\circ} \mathrm{C}$ for $5 \mathrm{~min}$, denaturation at $95^{\circ} \mathrm{C}$ for $30 \mathrm{~s}$, annealing at $51^{\circ} \mathrm{C}$ for $30 \mathrm{~s}$, elongation at $72^{\circ} \mathrm{C}$ for $1 \mathrm{~min} 30 \mathrm{~s}$, and post-elongation at $72^{\circ} \mathrm{C}$ for $10 \mathrm{~min}$. The denaturation cycle, annealing, and elongation were done 25 times, after which the obtained PCR products were electrophoresed on a $2.0 \%$ agarose gel with Gel Stain (TransGen Biotech).

Quantitative analysis of target mRNA in transfected HeLa cells. The quantification of target mRNA in transfected cell reagent (Table 2) was achieved using TransStart Green Tip qPCR SuperMix (TransGen Biotech). The thermal cycler conditions for qPCR analysis were as follows: pre-denaturation at $94^{\circ} \mathrm{C}$ for $30 \mathrm{~s}$, denaturation at $94^{\circ} \mathrm{C}$ for $5 \mathrm{~s}$, and annealing and elongation at $60^{\circ} \mathrm{C}$ for $30 \mathrm{~s}$ using a CFX96 real-time PCR (Biorad, USA). The denaturation cycle and annealing, and elongation were run 40 times. The melting curve was plotted by heating from $60^{\circ} \mathrm{C}$ to $95^{\circ} \mathrm{C}$ for $5 \mathrm{~s}$ with $0.5^{\circ} \mathrm{C}$ intervals, at each of which the plates were read. The amplification product of the human gapdh gene using the GAPDH-For and GAPDH-Rev primers was used as the internal control and plasmid pEGFP-env-tm JDV as the positive control. 
Table 2. The summary of experiments

\begin{tabular}{|c|c|c|}
\hline Experiment & Descriptions & Parameters \\
\hline \multicolumn{3}{|l|}{ 1.Cytotoxicity Assay } \\
\hline Untreated & untreated cells & \multirow{4}{*}{$\begin{array}{l}\text { Relative viability to untreated } \\
\text { cells }\end{array}$} \\
\hline DNA & pEGFP-env-tm JDV only & \\
\hline CS & chitosan solution only & \\
\hline CS-DNA & pEGFP-env-tm JDV with chitosan complex (1:2 wt./wt.) & \\
\hline \multicolumn{3}{|c|}{ 2.In vitro transfection assay and observation of GFP fusion protein } \\
\hline Untreated & untreated cells & \multirow{6}{*}{$\begin{array}{l}\text { Presence of fluorescence of } \\
\text { eGFP under microscope }\end{array}$} \\
\hline CS & chitosan solution only & \\
\hline DNA & pEGFP-env-tm JDV only & \\
\hline NTC8685-eGFP/liposome & positive plasmid encoding eGFP with liposomal agent & \\
\hline DNA/liposome & pEGFP-env-tm JDV with liposomal agent & \\
\hline DNA/CS complex & pEGFP-env-tm JDV with chitosan complex (1:2 wt./wt.) & \\
\hline \multicolumn{3}{|c|}{ 3.Qualitative detection of target mRNA in transfected HeLa cells } \\
\hline Untreated & untreated cells & \multirow{6}{*}{$\begin{array}{l}\text { Presence of specific product of } \\
\text { RT-PCR }\end{array}$} \\
\hline CS & chitosan solution only & \\
\hline DNA & pEGFP-env-tm JDV only & \\
\hline DNA/EL & pEGFP-env-tm JDV with non-liposomal agent & \\
\hline DNA/Liposome & pEGFP-env-tm JDV with liposomal agent & \\
\hline DNA/CS complex & pEGFP-env-tm JDV with chitosan complex (1:2 wt./wt.) & \\
\hline \multicolumn{3}{|c|}{ 4.Quantitative analysis of target mRNA in transfected HeLa cells } \\
\hline DNA & pEGFP-env-tm JDV only & \multirow{4}{*}{ Relative mRNA expression } \\
\hline $\mathrm{DNA} / \mathrm{EL}$ & pEGFP-env-tm JDV with non-liposomal agent & \\
\hline DNA/Liposome & pEGFP-env-tm JDV with liposomal agent & \\
\hline DNA/CS complex & pEGFP-env-tm JDV with chitosan complex (1:2 wt./wt.) & \\
\hline
\end{tabular}

\section{Results}

Gene design for DNA vaccine and plasmid preparation. The transgene was chemically synthesised and cloned into the pEGFP-C1 vector with restriction sites of $B g l \mathrm{II}$ and EcoRI to construct the pEGFP-env-tm JDV. Then, the plasmid pEGFP-env-tm JDV was transformed into $E$. coli DH5 $\alpha$ for largerscale production. Two selected kanamycin-resistant bacteria were checked by colony-PCR with the EnvFor and Env-Rev primers and showed a specific band of $336 \mathrm{bp}$, (Fig. 2A.). The selected positive clones were also confirmed using restriction analysis to give two distinct bands: a backbone vector $(4,700 \mathrm{bp})$ and the env-tm fragment of 1,098 bp, (Fig. 2B). Afterwards, one selected clone underwent further confirmation with sequencing using the EGFP-C and SV40pA primers. The alignment between the result of sequencing and the initial synthetic transgene showed that after transformation there is no mutation in the coding sequence of env-tm in the plasmid (supplementary data 2).

Chitosan-DNA complex preparation. The formation of chitosan-DNA complex was first observed with a gel retardation assay on agarose gel electrophoresis (Fig. 3). Several different mass ratios of DNA and chitosan were used:1:0.5, 1:1.0, 1:2.0, 1:3.0, and 1:4.0 (wt./wt.), and all complexes were formed in the same total solution volume. The chitosan solution as a negative control cannot bind to the DNA dye, so it 
did not produce luminescence in the gel. The free plasmid DNA migrates into three DNA bands showing three different plasmid conformations. As the mass of chitosan increases in the formulation, the free DNA plasmid that is able to migrate also decreases. The luminescence of free plasmid DNA could still be detected in nanoparticles with a ratio of 1:0.5 and 1:1.0 but was not detected in the higher chitosan ratio solutions. The more chitosan that is added in the formulation, the more plasmid DNA is trapped to form a chitosan-DNA complex. From the visualisation in agarose gel, the 1:2 mass ratio is the minimum ratio of chitosan to capture the entire amount of DNA plasmid. For that reason, this complex was further analysed with other parameters.

Physicochemical characterisation. Further characterisations were performed to investigate the physicochemical properties of the chitosan complex. The particle size of the complex was determined using dynamic light scattering (DLS) by measuring the random changes in the scattered light intensity from the solution. The result showed that the size of chitosanDNA plasmid complexes in the solution varied, ranging from 100 to $1,000 \mathrm{~nm}$. The population of particles in the solution had an average particle size of $236 \mathrm{~nm}$. Another parameter in the particle distribution measurement revealed that the formed chitosan-DNA plasmid complex solution had a polydispersity index value of 0.267 (Fig. 4A). The measurement of potential zeta was also carried out to examine the surface charge of particle in solution. The potential zeta measurement showed that the particles in solution had a mean value of $+17.9 \mathrm{mV}$ (Fig. 4B).
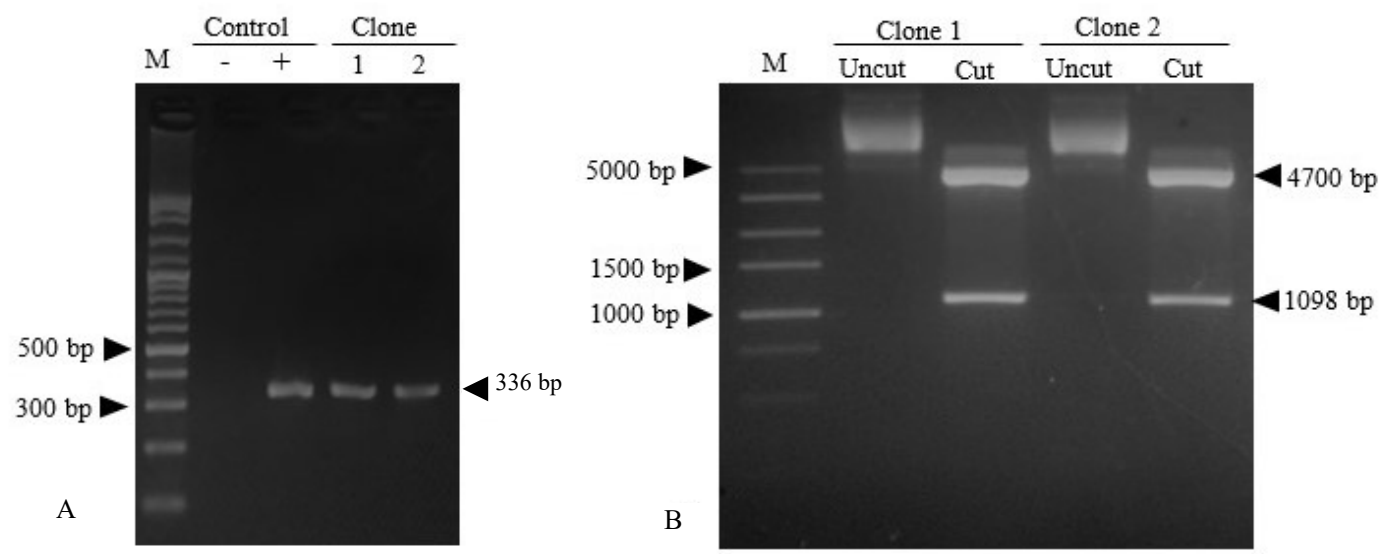

Fig. 2. The confirmations of transformed E. coli carrying pEGFP-env-tm JDV. Selection bacteria in LB agar with Kanamycin $50 \mu \mathrm{g} / \mathrm{ml}$ : A - The confirmation of two selected clones using colony-PCR. Untransformed bacteria (control -) plasmid with env-tm gene (control + ) and two colonies that were randomly picked from selection media (clones 1 and 2). B - Restriction analysis using EcoRI and BglII with undigested plasmid (uncut) and digested plasmid (cut)

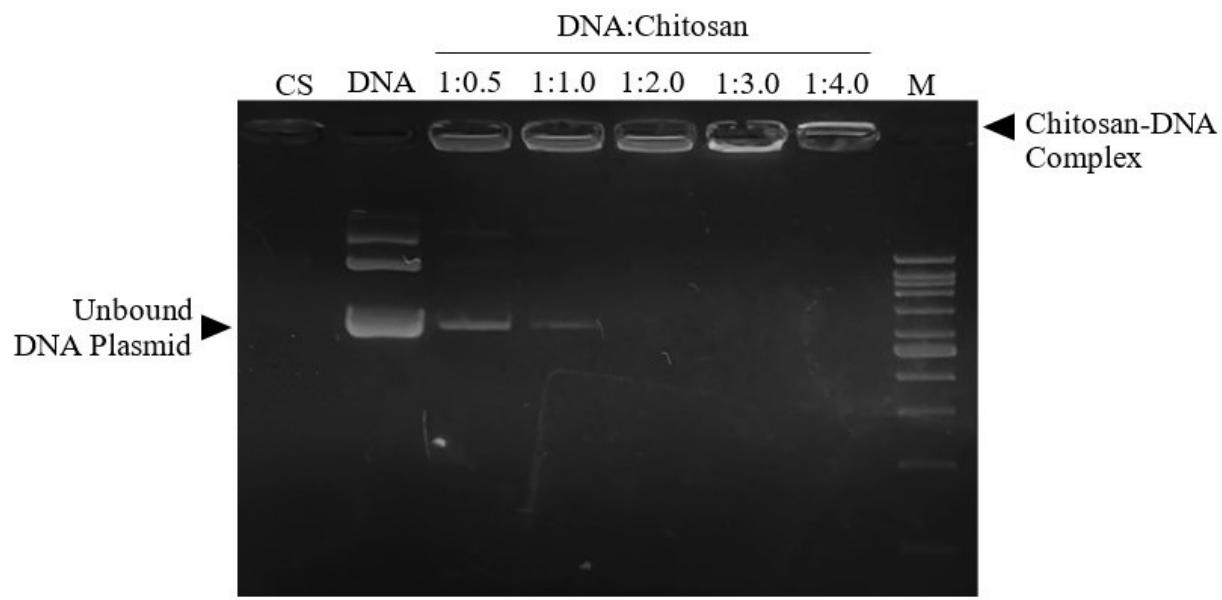

Fig. 3. Agarose gel retardation assay of chitosan-DNA plasmid complexes. The complexes contained $1,000 \mathrm{ng}$ pEGFP plasmid with different amounts of chitosan. The same amount of this plasmid (DNA) and chitosan-only solution (CS) were used as control. The chitosan-DNA complexes could not migrate in gel agarose and stayed at the wells (indicated with black arrows) 

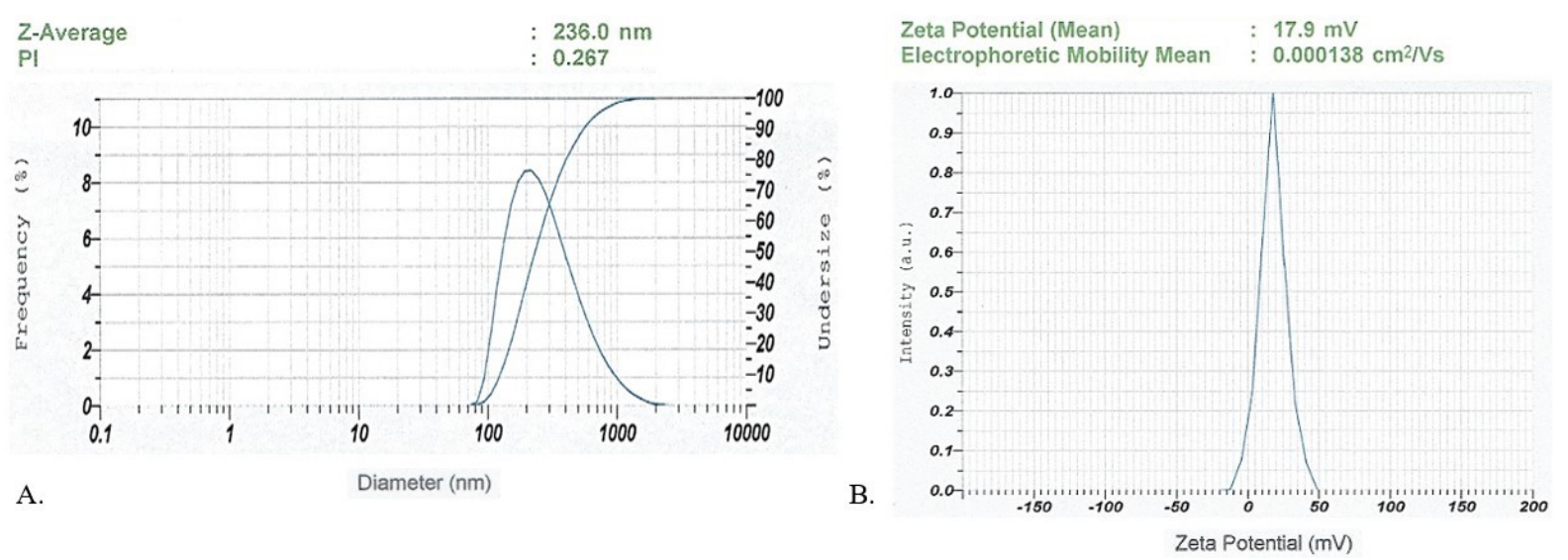

Fig. 4. Physicochemical characterisation analyses of chitosan-DNA plasmid complex: particle size distribution (A) and zeta potential value measurement (B)



Fig. 5. Relative viability of HeLa cells with chitosan-DNA complex. Each point represents the mean \pm SD of three determinations

Cytotoxicity assay. Prior to the in vitro transfection assay, the cytotoxicity assay must be investigated to ensure that no transfecting agent in the assay has a high toxicity potential for the cell. In the cytotoxicity assay, the cell line used for the assay was incubated with a defined concentration of transfecting agents and with the same incubation time as in the transfection assay. Untreated cells were used as a negative control. The viability of the cells that were incubated with cationic liposome, EL reagent, chitosan, cationic liposome-DNA complex, EL reagent-DNA complex, and chitosan-DNA complex were compared with the untreated cells. All procedures used in this experiment showed a relative cell viability that was higher than $80 \%$ (Fig. 5). When compared with the untreated cells, the treatments do not impact negatively powerfully enough to reduce the viability to under $80 \%$.

In vitro transfection assay and observation of GFP fusion protein. As a fast means of detection for the success of the gene delivery into the cells, the expression of GFP-Env-TM fusion protein was examined under a confocal microscope. The observation of untreated HeLa cells and transfected HeLa cells with chitosan and DNA plasmid alone showed no green luminescence (Fig. 6A-C). Furthermore, a considerable amount of luminescence was found in the positive controls using the commercial plasmid NTC8685-eGFP with the cationic liposomal delivery system (Fig. 6D). The use of this control plasmid serves to ensure that the design of this transfection experiment can produce observable luminescence under a confocal microscope. This was not the only confirmation because the delivery of pEGFP-env-tm JDV with the cationic liposomes-DNA complex was performed as a control to ensure that the design of DNA vaccine can be used to produce observable luminescence (Fig. 6E). In this experiment, chitosan-DNA complex was able to demonstrate luminescence under a confocal microscope (Fig. 6F). The observation of this luminescence proves that the delivery of DNA with the chitosan nanoparticle delivery system was successful. 
Qualitative detection and quantitative analysis of target mRNA in transfected HeLa cells. The DNA vaccine has the coding sequence of env-tm JDV so that the successful delivery inside the cell would make the cells produce the desired mRNA. Negative controls, i.e. untreated cells and chitosan-treated cells do not show any amplified bands that correspond with the presence of the env-tm gene. The appearance of DNA bands in the sample treated with commercial transfecting agents and the chitosan-DNA complex showed that the HeLa cells were able to produce the desired mRNA because of the successful transfection (Fig. 7A). In addition, samples with DNA treatment alone did not produce DNA bands, indicating that the use of DNA alone without any delivery agent in this study did not succeed in delivering DNA into cells. Expression of gapdh mRNA from all samples was also determined with reverse-transcriptase PCR as internal controls, and the quantification of mRNA expression was carried out with the same assay. The calculation of the target mRNA expression level was made from its normalisation value against the expression of the internal control gene (with calculation mode $\Delta \Delta \mathrm{Cq}$ ). The relative expressions to DNA only are shown in the histogram (Fig. 7B). The target mRNA expression of the non-liposomal transfecting agent was about 50 times higher than that of the chitosan-DNA complex, while the cationic liposomal transfecting agent was about 10 times higher.
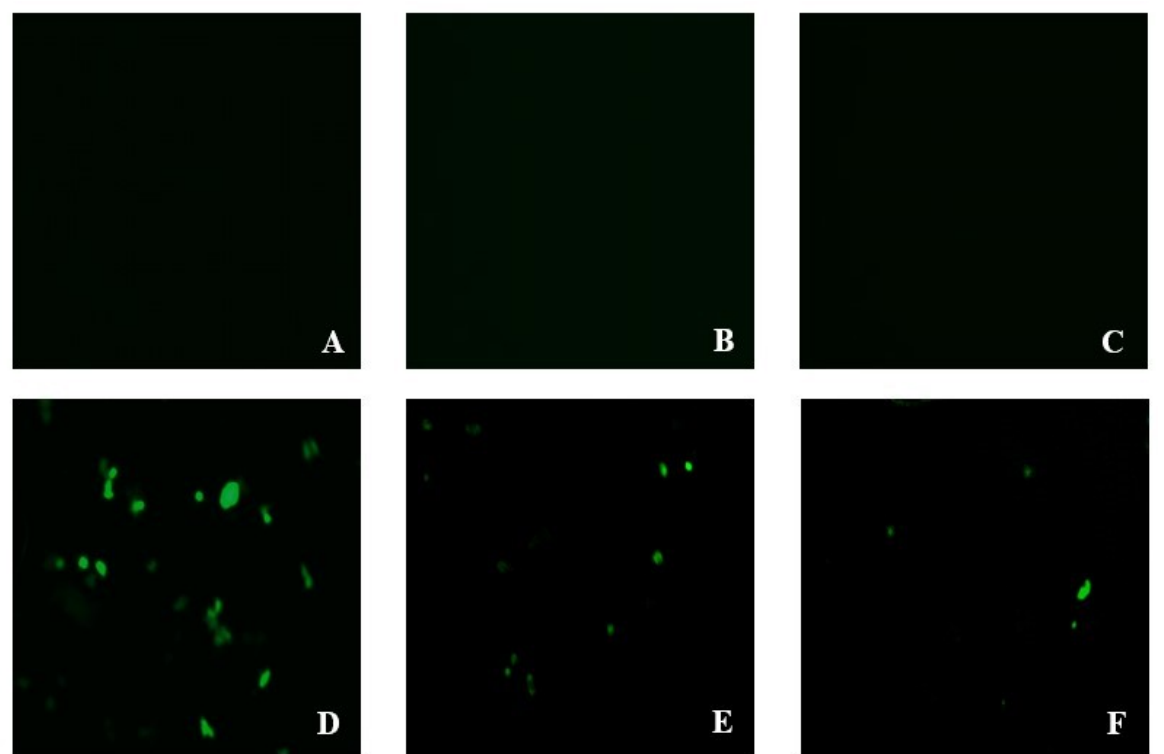

Fig. 6. Expression of green fluorescent protein in HeLa cells 24 h post transfection. A - untreated cells, B - transfection with chitosan only, C - with DNA plasmid only, D - control plasmid NTC8685-eGFP with cationic liposomal transfecting agent, E - plasmid pEGFP-env-tm JDV with cationic liposomal transfecting agent, and $\mathrm{F}$ - plasmid pEGFP-env-tm JDV in the form of chitosan-DNA complex

A.

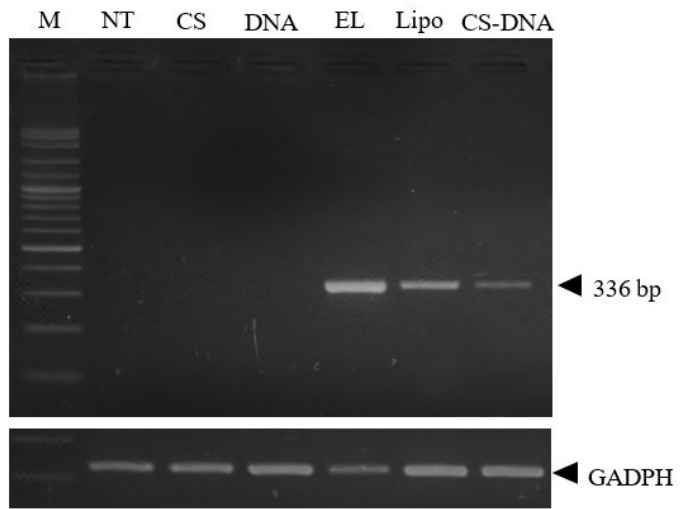

B.

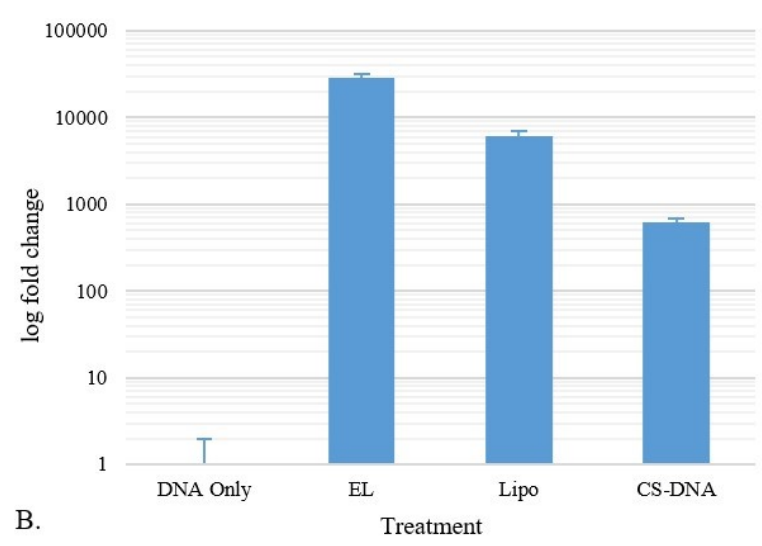

Fig. 7. Expression of target mRNA encoding Env-TM protein in transfected HeLa cells $24 \mathrm{~h}$ post transfection. A - The expression of target mRNA detected qualitatively using RT-PCR. B - The expression of target mRNA detected quantitatively using real-time PCR. NT - Untreated cells. CS - transfection with chitosan only. DNA - with DNA plasmid only. EL - plasmid pEGFP-env-tm JDV with non-liposomal transfecting agent. Lipo - cationic liposomal transfecting agent and CS-DNA - DNA in the form of chitosan-DNA complex. Each point represents the mean \pm SD of two determinations 


\section{Discussion}

The pEGFP-C vector has been previously used as a DNA vaccine vector to overcome disease caused by Toxoplasma (30). In this study, pEGFP-C1 was used exclusively to encode the transmembrane portion of an envelope protein from JDV that had been isolated before (14) to make a new DNA vaccine candidate. Additionally, this article also focuses on examining the success of its delivery in the form of chitosan complex. This form has been widely used in the pharmaceutical world as a carrier agent capable of releasing controlled molecules such as DNA, vaccines, peptides, or antibiotics (21). Chitosan is able to extend the residence time of the drug agent on the target site and protects the DNA from nuclease digestion inside the organism (11), so this delivery system is preferred under in vivo conditions to prolong the life of plasmid DNA in organisms. This experiment evaluated this complex as a delivery system at in vitro level by transfecting it into a HeLa cell line as a model to test the delivery of DNA vaccine across membrane cells. The success of DNA delivery was examined by observing the luminescence of antigen proteins that had fused with GFP protein in its N-terminal side. Finally, the expression of the mRNA that encoded this protein was qualitatively and quantitatively assessed with PCR.

There are four genes from JDV that have been used to develop DNA vaccine candidates: env, gag, rev, and tat (6). This study focuses on the envelope protein, one of the structural proteins that have two domains, surface, (SU) and transmembrane (TM). The entire sequence that encodes the transmembrane portion was previously isolated from JDV-infected cattle, including the highly hydrophobic C-terminal region (14). The optimisation of this gene was suggested to improve the expression of Lentivirus gene in a eukaryotic host (9). Furthermore, some unique sequences were prudent to omit to prevent lower propagation in host cloning or lower expression of heterologous protein in the host (26). Prior to the preparation of complexes, the propagated plasmid from the clone was confirmed to ensure that there was no mutation occurring after the transformation process into the cloning host.

The size of chitosan complexes in the solution varied from 100 to $1,000 \mathrm{~nm}$, but the population had a mean size of $236 \mathrm{~nm}$, with a PI value of 0.267 (Fig. 4A). The size of the chitosan-DNA complex as measured using coacervation complex techniques ranged from 100 to $250 \mathrm{~nm}(8)$, so in this study the formed complexes had the standard size (29). Other chitosanDNA complexes were also produced with similar methods, resulting in particles with sizes of 227.1 (29), 229 , and $282.8 \mathrm{~nm}$ (27). PI values indicate how large the particle size distribution system is. A high value indicates that the solution has a wide distribution and large particles so that it can precipitate, while a low PI value indicates a solution with a narrow (uniform) particle distribution. PI was valued at 0.01 to 0.7 for monodispersed systems, whereas PIs worth above 0.7 were said to have too large particle size distributions (13). Nanoparticles produced in this study had a pI value of 0.267 which is in the range of uniform particles. Beside the size, these complexes had an overall positive charge coming from the ionised chitosan amino group at $\mathrm{pH}$ 5. These positively charged complexes are easily attached to the negatively charged cell membrane and help the promotion of complex internalisation through endocytosis (27).

Prior to the transfection assay, a cytotoxicity assay was performed to assess the toxicity potential from chitosan complexes during exposure time with the cells. Chitosan solution and chitosan-DNA complex showed relative viability higher than $80 \%$ (Fig. 5). The use of similar chitosan complexes that gave relative viability ranging from $80 \%$ to $90 \%$ was still assessed to have no cellular toxicity potential (16). The acid $\mathrm{pH}$ factor $(\mathrm{pH} 5)$ of the nanoparticle-carrying agent solution had little effect on the culture medium because the medial culture had a bicarbonate buffer system which maintained a $\mathrm{pH}$ of about 7.4. This test indicated that chitosan complex did not exhibit a high toxicity potential for the cell during $4 \mathrm{~h}$ of exposure.

The transfection assay indicated that delivery using the chitosan-DNA complex succeeded in bringing plasmid DNA into the cells and expressed to mRNAs which could be detected using RT-PCR and real-time PCR. However, there was a considerable difference when compared to the commercial transfecting agent complex. This phenomenon was thought to be due to the slower release of plasmids from the chitosan complex, so we could only detect relatively fewer expression values in chitosan-treated cells. The DNA plasmid encapsulated by chitosan will be released in a controlled manner by polymer hydration process and polymer opening over time (17). The plasmid DNA on the surface of the chitosan nanoparticles will emerge rapidly from the nanoparticles in the first $3 \mathrm{~h}$, while at physiological $\mathrm{pH}$, while the rest will be released constantly up to $72 \mathrm{~h}$ with a DNA release of $70 \%$ of the initial quantity (17). Longer-term expression observations are likely to show higher gene expression as compared with $24 \mathrm{~h}$ observation. Chitosan-DNA complexes with a higher chitosan mass ratio are likely to produce better complexes. A higher chitosan mass ratio is able to produce particles with smaller diameter. By increasing the ratio of chitosan/DNA mass from $2: 1$ to $200: 1$, it was possible to decrease particle diameter from $181.9 \mathrm{~nm}$ to $94.1 \mathrm{~nm}$ (29). The decrease in particle diameter was expected to facilitate the uptake of particles by cells. In addition, increasing the mass ratio of chitosan/DNA can increase the positive value of the zeta potential of particles. A more positive charge will make it easier to attach the particles to the cell membrane that is negatively charged. By increasing the ratio of chitosan/DNA mass from $2: 1$ to $200: 1$, it was also possible to decrease the zeta potential from $+35.4 \mathrm{~nm}$ to $+41.2 \mathrm{~nm}(29)$. 
This experiment demonstrates that plasmid pEGFPenv-tm JDV as a candidate vaccine can be delivered as the chitosan-DNA complex and be expressed in the transcription level in vitro. However, the quantitative analysis using a real-time PCR showed that the delivery with chitosan complex resulted in lower target mRNA expression when compared with commercial transfecting agent. This initial study on in vitro level will be used for further improvement and evaluation in vivo.

Conflict of Interests Statement: The authors declare that there is no conflict of interests regarding the publication of this article.

Financial Disclosure Statement: This work was supported by the Indonesian Endowment Fund for Education (LPDP) through the LPDP Scholarship for masters students and by the Directorate General of Higher Education (DIKTI), Ministry of Education and Culture of Indonesia (grant number 1906/UN1/DITLIT/ DIT-LIT/LT/2018).

Animal Rights Statement: None required.

\section{References}

1. Budiarso I.T., Hardjosworo S.: Jembrana disease in Bali cattle. Aust Vet J 1976, 52, 97-97.

2. Burkala E.J., Narayani I., Hartaningsih N., Kertayadnya G., Berryman D.I., Wilcox G.E.: Recombinant Jembrana disease virus proteins as antigens for the detection of antibody to bovine lentiviruses. J Virol Methods 1998, 74, 39-46.

3. Chadwick B.J., Desport M., Brownlie J., Wilcox G.E., Dharma D.M.N.: Detection of Jembrana disease virus in spleen, lymph nodes, bone marrow and other tissues by in situ hybridization of paraffin-embedded sections. J Gen Virol 1998, 79, 101-106.

4. Chen H., Wilcox G., Kertayadnya G., Wood C.: Characterization of the Jembrana disease virus tat gene and the cis- and transregulatory elements in its long terminal repeats. J Virol 1999, 73, 658-666.

5. Craigo J.K., Montelaro R.C.: Lessons in AIDS vaccine development learned from studies of equine infectious anemia virus infection and immunity. Viruses 2013, 5, 2963-2976.

6. Ditcham W.G.F.: The development of recombinant vaccines against Jembrana disease, Murdoch University 2007, http://researchrepository.murdoch.edu.au/id/eprint/438.

7. Ditcham W.G.F., Lewis J.R., Dobson R.J., Hartaningsih N., Wilcox G.E., Desport M.: Vaccination reduces the viral load and the risk of transmission of Jembrana disease virus in Bali cattle. Virology 2009, 386, 317-324.

8. Gregory A.E., Titball R., Williamson D.: Vaccine delivery using nanoparticles. Front Cell Infect Microbiol 2013, 3, doi: 10.3389/fcimb.2013.00013.

9. Haas J., Park E.C., Seed B.: Codon usage limitation in the expression of HIV-1 envelope glycoprotein. Curr Biol 1996, 6, 315-324.

10. Hartaningsih N., Wilcox G.E., Dharma D.M.N., Soetrismo M.: Distribution of Jembrana disease in cattle in Indonesia. Vet Microbiol 1993, 38, 23-29.

11. Hashimoto M., Yang Z., Koya Y., Sato T.: Chitosan. In: Non-viral Gene Therapy: Gene Design and Delivery, edited by Taira K., Kataoka K., Niidome T., Springer-Verlag, Tokyo, Japan, 2005, pp. 63-74.
12. Issel C.J., Horohov D.W., Lea D.F., Adams W.V., Hagius S.D., McManus J.M., Allison A.C., Montelaro R.C.: Efficacy of inactivated whole-virus and subunit vaccines in preventing infection and disease caused by equine infectious anemia virus. J Virol 1992, 66, 3398-3408.

13. Kharia A.A., Singhai A.K., Verma R.: Formulation and evaluation of polymeric nanoparticles of an antiviral drug for gastroretention. Int J Pharm Pharm Sci 2012, 4, 1557-1562.

14. Kusumawati A., Hidayat B., Sardjono B., Widada J.S.: Isolationamplification of env-tm subunit genes of Jembrana disease virus by a single step RT-PCR and its direct cloning in pCR2.1TOPO plasmid. Buletin Peternakan 2012, 27, 1-7, doi: 10.21059/buletinpeternak.v27i1.1459.

15. Leutenegger C.M., Hofmann-Lehmann R., Holznagel E., Cuisinier A.M., Wolfensberger C., Duquesne V., Cronier J., Allenspach K., Aubert A., Ossent P., Lutz, H.: Partial protection by vaccination with recombinant feline immunodeficiency virus surface glycoproteins. AIDS Res Hum Retroviruses 1998, 14, 275-283.

16. Martien R., Loretz B., Thaler M., Majzoob S., BernkopSchnürch A.: Chitosan - thioglycolic acid conjugate: an alternative carrier for oral nonviral gene delivery? J Biomed Mater Res A 2007, 82, 1-9.

17. Masotti A., Bordi F., Ortaggi G., Marino F., Palocci C.: A novel method to obtain chitosan/DNA nanospheres and a study of their release properties, Nanotechnology 2008, 19, doi: https://doi.org/10.1088/0957-4484/19/05/055302.

18. Pachuk C.J., McCallus D.E., Weiner, D.B., Satishchandran C.: DNA vaccines challenges in delivery. Current Curr Opin Mol Ther 2000, 2, 188-198.

19. Pearson L.D., Poss M.L., Demartini J.C.: Animal lentivirus vaccines: problems and prospects. Vet Immunol Immunopathol 1989, 20, 183-212.

20. Siegert W., Nitsche A.: Guideline to reference gene selection for quantitative real-time PCR. Biochem Biophys Res Commun 2004, 313, 856-862.

21. Sinha V., Singla A., Wadhawan S., Kaushik R., Kumria R., Bansal K., Dhawan S.: Chitosan microspheres as a potential carrier for drugs. Int J Pharm 2004, 274, 1-33.

22. Soeharsono S., Wilcox G.E., Dharma D.M.N., Hartaningsih N., Kertayadnya G., Budiantono A.: Species differences in the reaction of cattle to Jembrana disease virus infection. J Comp Pathol 1995, 112, 391-402.

23. Wang G., Pan L., Zhang Y.: Approaches to improved targeting of DNA vaccines. Hum Vac Immunother 2011, 7, 1271-1281.

24. Wilcox G.E., Chadwick B.J., Kertayadnya G.: Recent advances in the understanding of Jembrana disease. Vet Microbiol 1995, 46, 249-255.

25. Wilcox G.E., Soeharsono S., Dharma D.M.N., Copland J.W.: Jembrana disease and the bovine lentiviruses. Aciar Proc 1997, $75,10-75$.

26. Williams J.A.: Vector design for improved DNA vaccine efficacy, safety, and production. Vaccines 2013, 1, 225-249.

27. Winarti L., Martien R., Sismindari: Formulation of nanoparticles from short chain chitosan as gene delivery system and transfection against T47D cell line. Majalah Farmasi Indonesia 2011, 22, $204-211$.

28. Xu K., Ling Z.Y., Sun L., Xu Y., Bian C., He Y., Lu W., Chen Z., Sun B.: Broad humoral and cellular immunity elicited by a bivalent DNA vaccine encoding $\mathrm{HA}$ and NP genes from an $\mathrm{H} 5 \mathrm{~N} 1$ virus. Viral Immunol 2011, 24, 45-56.

29. Ye Y., Xu Y., Liang W., Leung G.P.H., Cheung K., Zheng C., Chen F., Lam J.K.W.: Permeability across Calu-3 cells. J Drug Target 2013, 2330, 1-13.

30. Zhou J., Wang L., Lu G., Zhou A., Zhu M., Li Q., Wang Z., Arken M., Wang A., He S.: Epitope analysis and protection by a ROP19 DNA vaccine against Toxoplasma gondii. Parasite 2016, $23,17$. 